\title{
Bucharest Drivers' Perception of Navigation Apps and their Impact on Road Traffic
}

\author{
Ruxandra MOCANU
}

Faculty of Geography, University of Bucharest, Romania

\begin{abstract}
Bucharest is one of the most affected cities in the world in terms of road traffic congestion and under these conditions, drivers are constantly looking for new strategies to help them cope with daily traffic. They are increasingly relying on more on navigation applications installed in their smartphones with GPS capabilities. This research aims to investigate drivers' perception of the way they use navigation applications and their purpose, especially Waze, their perception of the impact of these applications on traffic and the city or even on socialization (socialization through the application or the socializing effects of the application itself). The study conducted in 2018 reveals the positive perception of the impact that the application has and highlights its new affordance, drivers using it as a socialization tool, a utility that was not initially intended.
\end{abstract}

Keywords: navigation applications, mobility, traffic congestions, road traffic

\section{INTRODUCTION}

Bucharest is one of the most affected cities in the world in terms of road traffic congestion according to the TomTom Traffic Index report. Traffic congestion is not just a problem during peak hours (data collected in 2014 show that this indicator becomes $84 \%$ on Tuesday mornings and $87 \%$ on Friday evenings) but almost all day long. In addition, a specific characteristic is that the congestion on secondary roads is much higher than congestion on main roads. According to the evaluation made in the Sustainable Urban Mobility Plan 2016 - 2030, one of the most important causes is the increase of road traffic in a network that does not keep pace, in the Bucharest-Ilfov region even more than in most of the country. In theoretical models, most traffic should be on express roads and arterial streets, the golden rule being $30 \%$ of roads take over $70 \%$ of traffic but in Bucharest, the main roads have certain impediments - parking, public transport - that prevent them from functioning as important arteries.

Under these conditions, traffic participants are constantly looking for new navigation methods and tools to help them cope with daily traffic, so drivers have become increasingly reliant on navigation applications installed on smartphones with GPS capabilities.

A research on habits and attitudes in road traffic in Romania shows that, nationally, at the end of 2018, 4 out of 5 traffic participants said they used navigation applications to deal with road traffic.

This research aims to investigate the drivers' perception of the purpose and way they use navigation applications, especially Waze, their perception of the impact of these applications on traffic and the city or even on socialization (socialization through the application or the socializing effects of the application itself).

\section{A BRIEF HISTORY OF NAVIGATION APPLICATIONS}

The rapid development of integrated technology in the automotive industry brings significant changes in the experience of driving a vehicle. Thrift (2004) states that this experience has already entered our "technological unconscious". The development of transport systems includes the introduction of 
autonomous vehicles, which will soon render independent navigation instruments obsolete and they will be "completely absorbed" in the car (Fisher, 2013)

Currently, the number of navigation applications is very high, this being due, on the one hand, to the development of infrastructure, and on the other hand to technological progress, especially in terms of smartphones. If 8 years ago, using an application like Google Maps on mobile phones was a challenge (processors were too slow, satellite connection was very weak), now most of these devices are able to provide a very good user experience.

This technological progress, but also the growing need of people to navigate in crowded cities have led to the emergence of a highly competitive market in the field of these applications. In addition to Google Maps (still the most used application of its kind), many others have appeared: Waze, Apple Maps, MapQuest etc, each offering specific features. Google Maps, for example, is based on a map created by its own means, while the Waze map is built on the information sent by users, so they are at the same time the creators and users of "real-time maps".

Some of the defining aspects of this current period include big data - collecting large volumes of data (either actively through crowdsourcing platforms on which we contribute voluntarily or passively, through our acceptance to let our activity monitored online and offline) and modeling processes based on the analysis of these data, the impact of online social networks on society - social media is being used in ways that shape politics, business, world culture, education, careers, innovation, and more but also to change processes through the growing presence of artificial intelligence in our intimate and everyday landscape (email services, navigation, etc.).

The concept of crowdsourced cartography, as defined by M. Dodge and R. Kitchin (2012), refers to the way in which the community is involved in the development and modeling of digital structures, voluntarily providing the information needed to manage various activities.
Crowdsourcing is also one of the principles on which the Waze application was developed. Used by drivers that contribute with real-time data, thus gaining superior accuracy to other applications, but also a much better representation of current traffic. But why are people willing to contribute without explicitly receiving something in return? The explanation offered by the above mentioned authors is that the application provides a platform that allows people to interact, communicate with each other and especially contribute collectively to achieve a common goal - an easier navigation through the jammed traffic of the crowded cities.

In the same article published in 2012, Dodge and Kitchin introduce the term "Prosumption", which is closely related to "crowdsourcing". Prosumption represents the quality of a person being, at the same time, both producer and user of the product.

Prosumption describes a special relationship that is created between the "provider" and the "prosumer": the latter does not receive any reward for the effort (other than intrinsic satisfaction, probably), and the provider does not have to hire (therefore pay) workforce, and even receives very valuable information from the social reality of users.

Lakhani and Boudreau (2013) proposed o model for the crowdsource approach (Figure 1)

\section{ABOUT SOCIAL NAVIGATION}

Hind and Gekker (2014) mention the developers of the Waze platform in the study "Outsmarting Traffic, Together: Driving as Social Navigation" as the ones who invented the term "social navigation" in the industry, defined by the development of "digital mapping platforms designed to foster automotive sociality."

They consider two aspects - one related to "playful" conceptualizations and refer to touchscreen satellite navigation platforms that include "gaming" as an inherent component of social relations with an example of the application of game-type mechanisms (rankings, avatars, bonus systems) and a second, which is more related to traffic driving policies and aimed at how drivers interact with digital interfaces. 


\section{When and How to Crowdsource}

To take full advantage of crowd-powered innovation, you need to understand what kinds of problems benefit most from open innovation and why. Here's a summary of the four main approaches you can use.

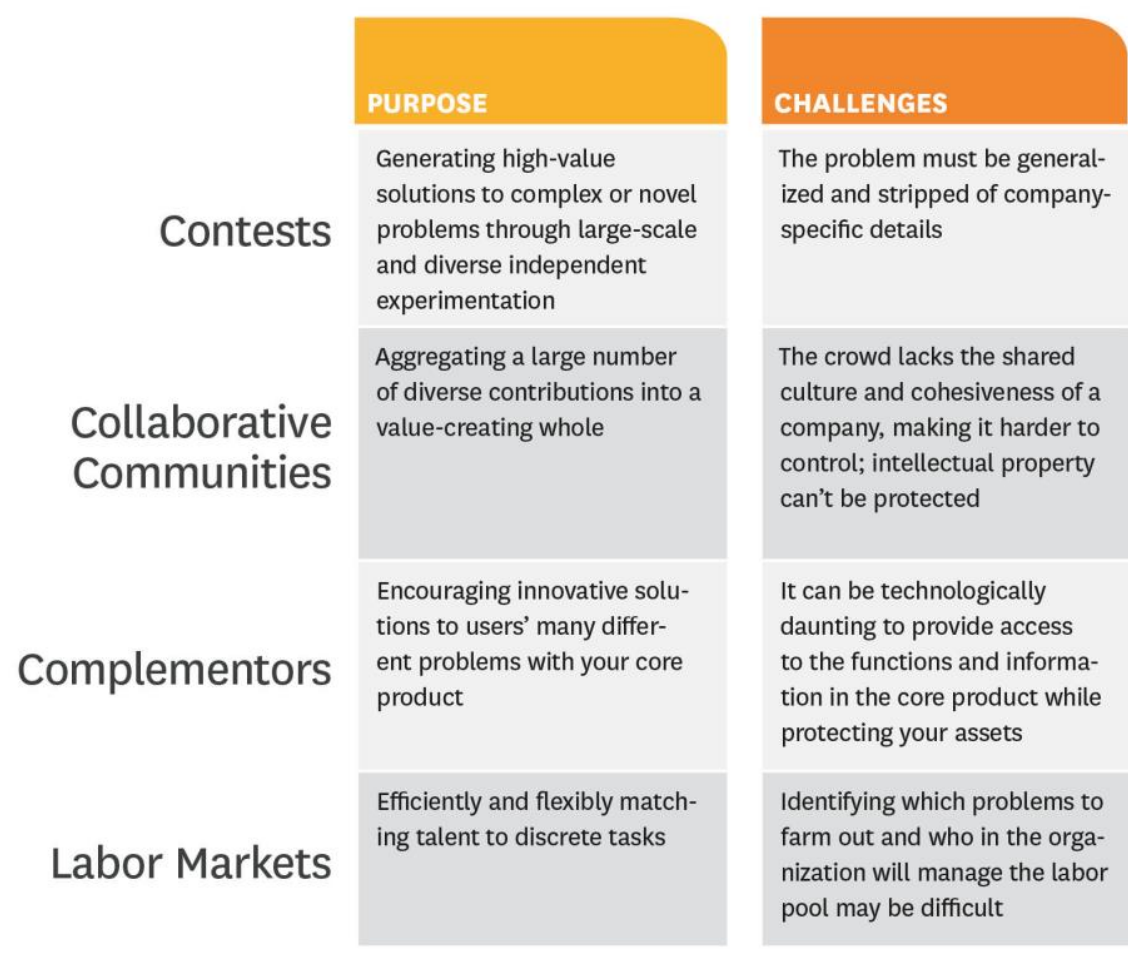

Fig. 1 Crowdsource approach model

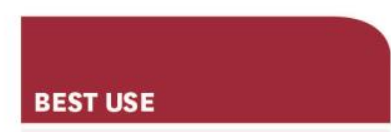

Highly challenging technical, analytical, and scientific problems; design problems; creative or aesthetic projects

Customer support communities; wikis; open-collaboration projects for information and software products with complementary assets inside the firm; FAQS

Open operational, product, or marketing data initiatives; content mashups; apps

Well-established categories of work that can be clearly described and evaluated; human computation; repeated tasks
In the same article, Sam Hind and Alex Gekker introduce another term - "casual politicking", which refers to the way in which the acquisition of practices specific to ordinary driving led to the emergence of the necessary conditions for the development of a special form of social policy, represented by in which each person can contribute, through digital, to the modeling of virtual reality.

To these two aspects, I add a third, prosociality under stress, and this is due to the fact that in the case of this study it is a specific local element traffic in Bucharest is associated with a high level of stress for drivers. Stress, although it can be seen as a challenge, as a maladaptive element, is a psychological mechanism that plays a key role in ensuring the survival of the body. According to the perspective presented in article The Social Dimension of Stress Reactivity (von Dawans et al., 2012), stress is the factor that determines the body to allocate the necessary resources to cope with a dangerous situation (fight or flight, for example).
In the same article, the authors present the concept of "stress" as a factor that facilitates or leads to the emergence of prosocial behavior and demonstrated this experimentally: they selected several students from the University of Zurich, whom they subjected, in laboratory conditions, to stressful situations and then by applying personality tests they were able to highlight aspects related to prosocial behavior. Following the experiment, a strong positive correlation was found between the presence of stress and prosociality (measured, in this research, by trust, "sharing behavior" and social interaction).

A study conducted in the US, "The Popularity of Google Maps: Trends in Navigation Apps in 2018" on a sample of 511 users who use at least 3 different applications daily reveals that over three quarters (77\%) of smartphone owners use navigation applications regularly - a result confirmed by a similar research in Romania. The same study indicates Google Maps as the most popular navigation application, followed by Waze. 
Most people use such applications because they offer better itineraries, so directing the preference to Waze is logical, they believe that Google Maps provides the best directions due to the quality of Google maps, collected through the Street View program and aerial images obtained by satellite.

A balanced approach implies that we will evaluate both the advantages and disadvantages of GPS navigation applications, considering that these can have negative consequences on the way drivers navigate, mainly due to a "blind" dependence that can endanger them.

Although Google Maps is currently the most used navigation application, not only, (Figure 3), only on the Waze application because we explore not only the navigation features but also aspects related to socialization.

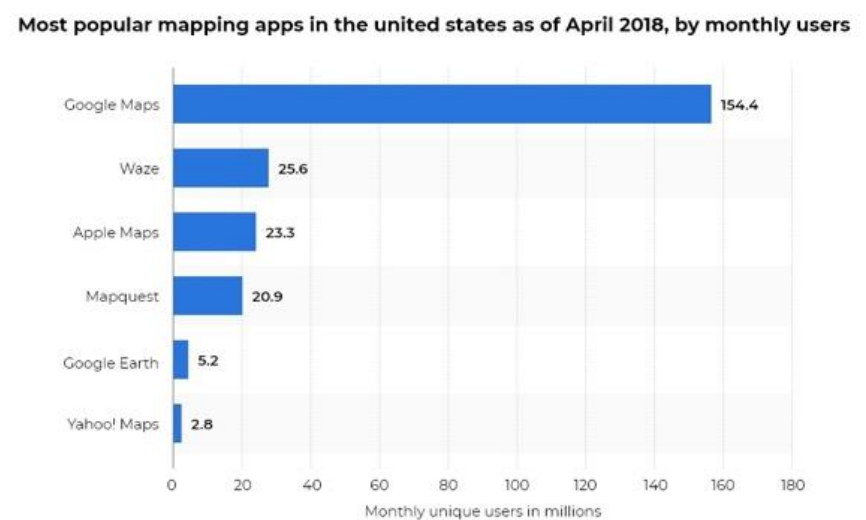

Fig. 3 Navigation apps usage in US, 2018

\section{ABOUT WAZE AND THE COMMUNITY}

Waze is a free, real-time navigation application, whose map was created by its users from scratch. In 2011, Waze had 10 million users, currently it has reached 130 million, a growth rate of 3-4 million per month and it is quite complicated to make a clear distinction between those who produce the map, those who edit it and those who use it. This large community has turned the application into a very accurate map, allowing users to alert each other about traffic events. Although initially the application was designed only for those who commute from home to work, Waze has become more than that, incorporating current trips to unknown destinations.

Waze calculates routes based on real-time traffic, but also based on the history of travel routes in the application. Routes are calculated by a server, the application itself being more of an interface.

As mentioned earlier, in the paragraph dedicated to the concept of Politicking in the Waze application, each user has political power. Anyone can use the options provided by the application, to bring virtual reality as close as possible to the current one and to constantly add relevant content. In a way, the accuracy of the application is the common goal of all users, so each of them is motivated to contribute the right information.

The idea of the "social navigation" application encourages detailed reporting of problems with the map, reporting under anonymity, but also relying on effective communication between users and publishers. Thus, Waze undertakes to correct the mistakes or inaccuracies of the addresses or to eliminate duplicates, all operations being performed through the reciprocity of the Waze database Google Maps.

Waze has transformed from a navigation tool into a platform that connects people around the world and contributes to the same goal, a greater good - making transportation better for everyone. Drivers are connected to each other and the app forms local communities to improve the quality of daily commutes. It is extremely important to note that the application is still powered by data maintained and distributed in a voluntary system of the user community.

Users can use the app passively (drivers who only drive with the app open) but also actively, either by sharing their traffic experience by reporting accidents, radars or other hazards, or by taking on the role of Waze editor.

The application offers the possibility to set destinations such as work, home or other frequently frequented locations, which can plan routes so that the user receives reminders of the time when he has to leave home in order to reach the destination on time.

Waze can be synchronized with the calendar and events on Facebook, thus receiving directions to navigate these events directly from the application or routes can be sent, preferably, to contacts in the friends list, with the option to follow the route live.

To encourage users to contribute as actively as possible, Waze has introduced a gamification 
module, specific to the world of gaming, in order to encourage the most active participation of users.

Waze started as an application that also provided a "game" component in addition to the functional one. The purpose of these components is different, they are for example either strategies to increase the engagement of users through different elements: the system of "conquering" the map and finding rewards offered by developers through which users can "evolve". The avatars in the application, improving their characteristics, as in an online game or strategies to complete as large as possible the map - the concept of "conquering" by moving on the map was supported and promoted by Waze by placing rewards in unexplored locations.

The scoring system that builds the rankings within the application offers a multitude of methods by which different actions can be capitalized: covering a large number of kilometers, signaling traffic situations, confirming them etc.

One of the essential dimensions of the application, which has remained constant, is that of the community. For example, joining a team can accessorize your avatar with a specific symbol or certain functions in the application, for example becoming an editor provides you with access to a certain category of accessories to personify the user.

Another option of the Waze application (perhaps the most relevant for this study) is the "chat" option. It gives users the opportunity to communicate, in a simple way.

\section{WAZE IN ROMANIA}

As everywhere in the world, the Waze Romania map was created by users, volunteer editors, from scratch and is managed by them. We do not have official data related to the number of users but we have an estimate of over 4 million users in 2018 and the "Waze Romania Community" (https://www. facebook.com/groups/WazeRomania) is a Facebook group that brings together over 21,000 users and map editors. In the online environment, information is also available on www.waze.ro and the Facebook pages of Waze Romania (www.facebook.com/ WazeRomania), Waze Info Trafic Romania, Waze Trafic Bucharest.

\section{ABOUT THE IMPACT OF WAZE}

Although Waze is not the most used navigation application (Google Maps being more used), it could be said that it has a strong influence on traffic. Being an application that works based on real-time feedback from users, Waze suggests detours, less crowded. The problem is that, often, the observance of these routes involves the use of secondary streets, adjacent to the main boulevards, and from here can arise the following problem: Waze users end up blocking the streets between apartment blocks, causing real inconvenience to residents and changing the traffic routines of a large number of people. In a way, it would seem that Waze is creating traffic where there wasn't any and changing some ecosystems.

The article "The Perfect Selfishness of Mapping Apps", written by Alexis Madrigal in 2018, highlights the idea that using applications like Waze is a selfish act, as this leads to artificially disrupting quiet areas.

In other words, people strictly follow their individual interest (that of getting to their destination as soon as possible), without caring about how it affects others.

This research does not aim to analyze the impact of the Waze application on those who live on the streets adjacent to the main boulevards, but we can say that, empirically, this effect exists and is quite significant in Bucharest. From the increase in the number of road accidents, to the change of traffic signs on the side streets (two-way streets became one-way streets, due to the fact that cars parked in those areas could get out of the parking lot only with great difficulty, in the context of rush hour traffic jams), it is clear that as a result of the massive use of the Waze application by drivers, there are significant changes in road traffic flows, and in the practices and routines of city dwellers.

\section{WAZE AND THE TRAFFIC IN BUCHAREST}

The poor infrastructure, as well as the increasing number of cars in Romania (and not only), lead to traffic congestions, both in big cities and on extraurban roads, it is obvious that traffic has become an important stressor. In Bucharest, for example, people make their daily schedule, choose their job, home, etc., depending on road traffic. 
As most Bucharest inhabitants (and not only) spend a lot of time stuck in traffic and Waze is (perhaps) the most used navigation application, we believe that it could have a fairly significant impact on the way social relations are conducted.

The application is built as an interactive map (interaction between man and map), relying heavily on user reports "many to one", but it was not designed with the intention of a social network (interaction between people). This statement is justified by the fact that the application provides users with numerous options for reporting traffic events, but for communication between users, a fairly rudimentary "chat" is available, compared to applications whose purpose has been since beginning, that of creating social networks and communities (even if the reports sent by users can also be defined as forms of interaction, they are implicit, not explicit - they are oriented towards a "greater good", not towards particular individuals.) Given the above, the study aims to find out whether Waze, despite technological limitations, can be a tool through which social relationships can be created, and the premise from which we start is that people will use the application, not only using the functions for which it was designed, but also to create social cohesion and to overcome stressful (traffic) situations more easily by using the chat function.

The aim of this study is to investigate how traffic participants use Waze, their perception of the impact these applications have on traffic and the city or even on socialization (application socialization or the socialization effects of the application itself).

The research methodology included a quantitative research conducted online during January $18-25$, 2018, data collected by completing a questionnaire with 12 questions that we distributed on Facebook on personal profiles and in various groups.

As of January 24, we had already collected over 500 responses and then we decided to add another dimension to our research. We added a more specific question to the questionnaire, intended for map editors and distributed it to the Waze Romania Community group, collecting data for 24 hours. During this time, we received over 600 new answers. When interpreting the data, we also tried to identify the differences between the responses of a general audience, Waze users, and a much more involved group.

\section{SAMPLE STRUCTURE}

A first observation is related to the composition of the study sample, although the distribution of the questionnaire was not made on a previously selected sample on the basis of representativeness, it was a relevant and balanced composition. The general gender distribution is correlated proportionally with the way in which driving licenses are distributed in Romania, respectively $30 \%$ women and $70 \%$ men, including the distribution within the sample from the Waze group - 9\% women and 91\% men who reflect correctly the studied group, the members being predominantly male.

Over $70 \%$ of those who answered the questionnaire are between the ages of 26 and 45 , and $68 \%$ of those in the Waze group are between the ages of 18 and 35 .

In both groups, the majority of respondents are amateur drivers (91\%) and spend between 30 minutes and 2 hours in traffic $(76 \%)$, and there is no difference between the two groups.

\section{WAZE USAGE}

The frequency distribution with which the two groups use the Waze application is similar, most of them being in the active consumption area as shown in Figure 4.

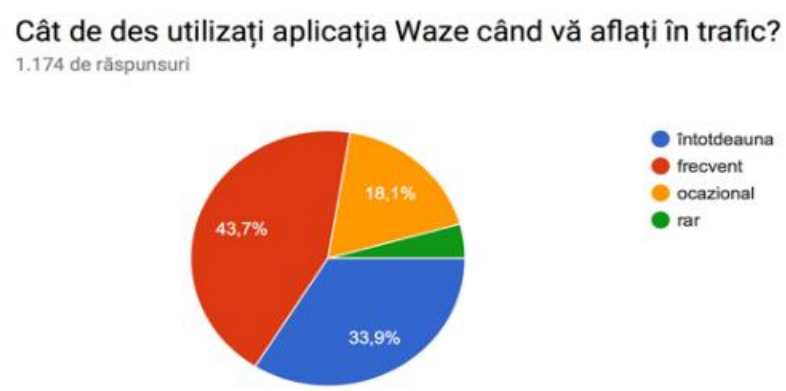

Fig. 4 How often do you use Waze while driving?

As for the level of confidence given, it is extremely high throughout the sample. The proportion 
of active users is obviously very high in the Waze group (83\%) and quite high in the case of the second group, $60 \%$, with an overall average of $72 \%$.

Regarding the way they actively use Waze, $75 \%$ are contributors and use it to signal the situations encountered in traffic in the application.

As for the perception of the impact of the application on the majority driving experience related to utility in navigating the city, followed by exploring the city (answers to the question "What is the impact that you think Waze has on your personal driving experience?") - most participants in both groups responded that Waze helps them reach their destination quickly and safely $(55 \%$ for the Waze Group (GW) and $48 \%$ for the general public (PG)), while $32 \%$ of GW and $27 \%$ of PG consider that the app helps them discover the city, showing them less frequented routes. The third option selected by the respondents was "it gives me the option to personally contribute to safer traffic". From the answers provided by the study participants we deduce that the Waze application is used due to the perception that it is efficient (indicates the route), is reactive (changes the route according to several parameters related to traffic) and is interactive (gives them the opportunity to actively involved in order to obtain a "safer" traffic).

Respondents believe that the most important impact that Waze has on urban traffic is to streamline traffic across the city, while very few believe that the application could have a detrimental effect on adjacent streets. This result seems to confirm the hypothesis set out in the article "The Perfect Selfishness of Mapping Apps", according to which users of these applications tend to ignore the fact that they could cause major discomfort to other people in order to achieve a personal goal.

We also introduced a social dimension to the study and explored how users interact. Most of the participants in the study do not interact with other users of the application, but $7 \%$ of them answered that they use the "chat" option to participate in public discussions or to get involved in games initiated by others and $5.7 \%$ use this option to exchange messages with friends.

Most people who use "chat" do so when they are stuck in traffic (30\%) or when they have a technical problem $(11 \%)$. The perception of the majority is that the application helps its users to reach their destination faster and safer (over $80 \%$ of participants).

The side effects of using the application in traffic are ignored, $85 \%$ of respondents said that Waze helps streamline traffic throughout the city, while only $22 \%$ believe that the effect of using the application is to crowd the streets adjacent to major boulevards.

\section{SOCIALIZATION}

When asked, "What is the purpose of using the Waze app?", most of the participants in this study answered that they use the app for the purpose for which it was created: traffic navigation. Just over $2 \%$ of respondents said they use the app to socialize with other people.

Regarding the use of the application (passive, only as a consumer of information and active, as an active provider of traffic data that includes situations, road conditions, etc.), most participants responded that they use the Waze application actively, contributing to reports or alerts about various road events, most of them use "chat" to send messages to other users in connection with traffic situations, and $7 \%$ use this option to get involved in games (such as word games) or in public discussions, while $5.7 \%$ use it to chat with friends, see Figure 5 for a chat example.

Up to this point, it can be said that the Waze application is not mainly used for direct interaction with other traffic participants, but, when asked about the context in which participants use "chat", most have chosen the option of answer "when I'm stuck in traffic."

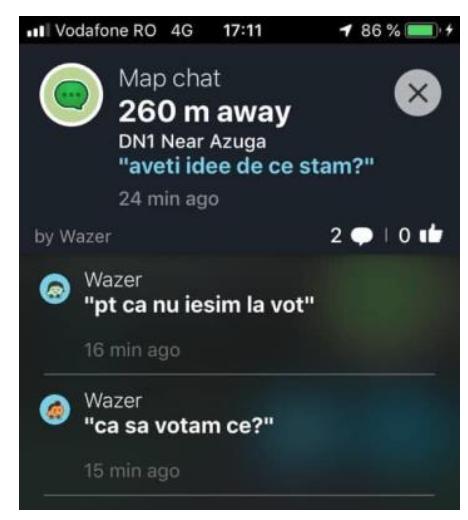

Fig. 5 Waze application screenshot-conversation 
From this information, we can deduce that, even if the application is not currently used explicitly for socialization purposes, by offering the option of a direct communication option between neighboring traffic participants, it is a fertile ground for the development of interpersonal interactions. These interactions do not occur in free-flowing traffic conditions, but when there are traffic jams.

One explanation could be that people tend to affiliate with those in a similar situation, thus alleviating some of the accumulated frustration. This hypothesis correlates with the theory stated in the introductory part, according to which, in stressful situations, people tend to manifest a prosocial behavior. In the case of Waze, this behavior could be represented by the use of an auxiliary feature of the application ("chat") for communication purposes. It is obvious that, in the conditions of blocked traffic, the role of a navigation application is non-existent, especially when it comes to long, extra-urban roads, but nevertheless, people remain connected to the application and initiate various forms of interaction, such as word games, as shown in Figure 6.

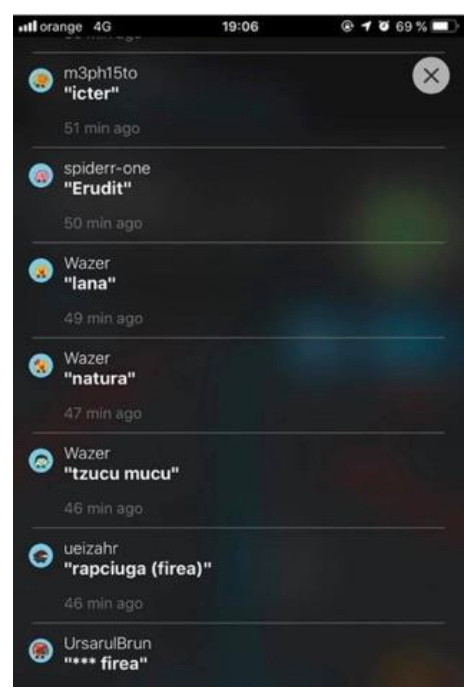

Fig. 6 Waze application screenshot - wordgame

Why not use other social networks, such as Facebook, when stuck in traffic? Probably one of the answers would be: Facebook does not meet, in these conditions, the need for affiliation. By using the Waze app, people only interact directly with those who are stuck in the same stretch of traffic (e.g. on highways, for example), and share the same feelings of frustration generated by a situation to which they are all connected. In this situation, the differences in status disappear and each person becomes just a simple participant in traffic and communication and social relations are much easier to establish, because other aspects related to age, profession, social class, disappear.

In conclusion, we can say that, although Waze is basically a navigation application, when the context demands it turns into a communication platform for drivers, a potential future social network.

\section{CONCLUSIONS}

Waze application is used mostly as a navigation tool, actively contributing with information and perceived as a useful tool in streamlining traffic throughout the city, disregarding the harmful effects on side streets adjacent to major boulevards. It is popular due to the perception that it is efficient and dynamic through route optimizations and interactive because it offers users the opportunity to get actively involved in order to obtain a "safer" traffic.

Regarding the psychological component, stressful situations can trigger prosocial behavior, but what could be the link between trafficking, Waze and pro-social behavior? Is this the new affordance of this navigation application? Using the chat option of the application can support this hypothesis, namely that Waze, despite technological limitations, can be a tool through which social relationships can be created.

\section{REFERENCES}

Dawans, B \& Fischbacher, U \& Kirschbaum, C \& Fehr,E \& Heinrichs, M. (2012). The Social Dimension of Stress Reactivity: Acute Stress Increases Prosocial Behavior in Humans. Psychological science. 23. 651-60. 10.1177/0956797611431576.

Dodge, M \& Kitchin, R. (2013). Crowdsourced cartography: Mapping experience and knowledge. Environment and Planning A. 45. 19-36. 10.1068 /a44484.

Fisher, A (2013) Inside Google's Quest To Popularize Self-Driving Cars. Popular Science, September 18.

Hall, F. (1992). Traffic Stream Characteristics. https://www.researchgate.net/publication/242405119 _Traffic_Stream_Characteristics 
Hind, S \& Gekker, A. (2014). 'Outsmarting Traffic, Together': Driving as Social Navigation. Exchanges: the Warwick Research Journal. 1. 165-180. 10.31273/eirj.v1i2.84.

Lakhani, K. and Boudreau, K. (2013). Using the Crowd as an Innovation Partner. [online] Available at: http://web.b.ebscohost.com.ezprod1.hul.harvard.e $\mathrm{du} /$ ehost/pdfviewer/pdfviewer?vid=1\&sid=6d13a76c -b7ad-40c5-b4b5-c1838fadd207\%40sessionmgr103

Thrift, N. (2004). Driving in the City. Theory Culture \& Society - THEOR CULT SOC. 21. 41-59. 10.1177/0263276404046060.

Obiceiuri și atitudini în traficul din România - December 2018. Study conducted by Merlin Research and the Titi Aur Academy for Continental Romania. https://www.continental.com/ro-

ro/presa/comunicate-de-presa/continental-ata-studiuobiceiuri-participanti-trafic-156262

TomTom Traffic Index Report https://www.tomtom. com/en_gb/traffic-index/ranking/

Planul de mobilitate urbană durabilă 2016-2030 Regiunea București - Ilfov http://www.pmb.ro/ servicii/transporturi_drumuri/docs/planul_de_mobili tate_durabila_2016-2030.pdf

https://themanifest.com/mobile-apps/popularity-googlemaps-trends-navigation-apps-2018

https://www.cars.com/articles/waze-of-seeing-studyshows-which-nav-systems-users-want-14207027 94058/?fbclid=IwAR2IOw4dwJWNDBORDOzWgH bQfDQvLjEuASmfiADPDCRv7CBM_R1QPgjn9og

https://www.theatlantic.com/technology/archive/2018/03 /mapping-apps-and-the-price-of-anarchy/555551/ ?fbclid=IwAR16SQTBmkiDGe0ryNO_ughyxDtJm2 9FwuSm2Gx1OFNzxyyDCSSfPZP2A_M

https://www.usnews.com/news/national-news/articles/ 2018-05-07/why-some-cities-have-had-enough-ofwaze

https://www.lamag.com/citythinkblog/waze-los-angelesneighborhoods/

https://www.bloomberg.com/news/articles/2019-11$12 /$ navigation-apps-changed-the-politics-of-traffic https://spectrum.ieee.org/computing/hardware/yournavigation-app-is-making-traffic-unmanageable https://digital.hbs.edu/platform-rctom/submission/howcrowdsourcing-is-changing-the-waze-we-drive/ 